\title{
SUPPORT EFFECT ON THE STRUCTURE AND PROPERTIES OF MANGANESE OXIDE ELECTRODE MATERIALS
}

\author{
Huatao Wu*, Yongjun Han, Li Wang, Lihui Zhang, and Xiang Wang \\ Department of Chemistry and Environmental Engineering, Pingdingshan University, Pingdinshan 467000, People’s Republic of China
}

Recebido em 16/05/2017; aceito em 29/08/2017; publicado na web em 16/10/2017

\begin{abstract}
The composite electrode material of manganese oxide supported on poly glucose (PGS) was prepared by using $\mathrm{KMnO}_{4}$ as manganese source. In order to study the influence of the support on the structure and properties of the composite electrode materials, the

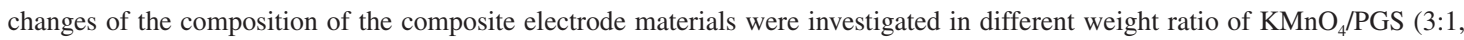
3:3, 3:5, 3:7, 3:9). The characterization results of XRD, Raman special and XPS indicated the composition of manganese oxides was greatly influenced by the content of PGS. When the PGS content is lower, the composition of manganese oxide in hybrid material is single-component oxide ( $\mathrm{MnOOH}$ or $\mathrm{Mn}_{3} \mathrm{O}_{4}$ ). With the increasing PGS content, a mixture of $\mathrm{Mn}_{3} \mathrm{O}_{4}$ and $\mathrm{MnCO}_{3}$ was observed, furthermore proportion of $\mathrm{MnCO}_{3}$ in mixture also increased, and up to higher PGS content $\left(\mathrm{KMnO}_{4} / \mathrm{PGS}=3: 9\right)$, single-component $\mathrm{MnCO}_{3}$ was founded on hybrid material. In addition, the change of composition of hybrid materials also led to an obvious difference in electrochemical performance. With the increase of PGS content, the specific capacitance of hybrid materials increases firstly, and reaches the maximum with the weight ratio of $\mathrm{KMnO}_{4} / \mathrm{PGS}$ equal to $3: 3$, and then gradually decreases. This was attributed to the higher electrochemical performance of $\mathrm{Mn}_{3} \mathrm{O}_{4}$ than that of $\mathrm{MnOOH}$ and $\mathrm{MnCO}_{3}$.
\end{abstract}

Keywords: manganese oxides; support effects; poly glucose; composite electrode material; electrochemistry.

\section{INTRODUCTION}

Owing to the increasing energy demanding and diminishing supplying of fossil fuel, considerable effort has been devoted to the development of alternative energy. Electrochemical energy storage systems with high power and energy density, such as rechargeable batteries and electrochemical capacitors (ECs), are receiving increasing consideration. ${ }^{1}$ As an intermediate system between dielectric capacitors and batteries, supercapacitors have attracted dramatic attentions in recent years for their apparent advantage including fast charge/discharge rate high stability and high power density. ${ }^{2-4}$ As for supercapacitors, well-engineered nanocomposites composed of nanostructured supports and redox active electrodes are critical to the achievement of high electrochemical performance.

Among various electrodes materials, manganese oxides and hydroxides with layered or tunnel structure, such as $\mathrm{MnO}_{2}, \mathrm{Mn}_{3} \mathrm{O}_{4}$, $\mathrm{Mn}(\mathrm{OH})_{2}$ and $\mathrm{MnOOH}$, are of the most promising candidates for their high specific capacitance, low cost and environment benignity. ${ }^{5-7}$ $\mathrm{MnO}_{2}$ with a layered structure is extensively studied because of its high theoretical specific capacitance. ${ }^{8} \mathrm{Mn}(\mathrm{OH})_{2}$ with similar layered structure like $\mathrm{MnO}_{2}$, can not only accommodate large number of ions but also greatly facilitate the diffusion of ions in it. ${ }^{9}$ As for $\mathrm{Mn}_{3} \mathrm{O}_{4}$, the coexistence of $\mathrm{Mn}^{2+}$ and $\mathrm{Mn}^{3+}$ makes it possible for the mutual transformation of $\mathrm{Mn}^{2+}$ and $\mathrm{Mn}^{3+}$ in the redox process, which means a great deal of active sites for ion absorption..$^{10}$ Therefore, this material may possess unique electrochemical performance. However, the manganese oxides nanomaterials are suffered from some disadvantages, such as poor electronic conductivity, easy aggregation and partial dissolution, which greatly hindered the application in electrodes. ${ }^{11,12}$

To improve the electrochemical performance, the porous carbon materials with high surface area and excellent electronic conductivity, such as graphene, carbon nanotubes, carbonfibers and mesoporous carbons, which are applied to prepare composite electrodes. ${ }^{13-15}$ The

*e-mail: wuhuataocn@163.com carbon substrates in composite electrodes act as highly conductive current collectors, meanwhile the interconnected porosity also provides continuous pathway for electrolyte diffusion, resulting in high electrochemical performance in comparison with single manganese oxides electrodes. Biomass as a carbonaceous precursor has been extensively investigated for its abundance, low cost and easy accessibility compared with other carbonaceous precursors. Recently, many attempts have been made to produce spherical carbon by hydrothermal synthesis using carbohydrate, such as glucose, sucrose and fructose. ${ }^{16-18}$ As an example, the carbon spheres using glucose by hydrothermal was synthesized at $160-250{ }^{\circ} \mathrm{C}$. During reaction process, the polymerization reaction and cross-linking reaction of glucose occurred and formed polymers intermediates, and then from here to the carbonaceous. ${ }^{17}$ The prepared carbon spheres surface have many oxygen group (mainly $-\mathrm{OH}$ and $-\mathrm{C}=\mathrm{O}$ ), benefited these groups, carbon spheres can be used as supports, loaded with metals and metal oxides, especially for transition metal oxides/ carbon spheres as supercapacitor electrodes. ${ }^{19,20}$

Generally, the preparation methods of manganese oxides/carbon composite electrodes were focused on depositing manganese oxides onto carbon substrates by using a variety of approaches, including physical mixing of the components, ${ }^{21}$ thermal decomposition, ${ }^{22}$ chemical deposition using precursors such as permanganate ${ }^{23}$ and electrochemical deposition..$^{24}$ In comparison with other preparation methods, chemical deposition could possibly maintain the porous structure of carbon substrates in preparation process, meanwhile high manganese oxides loading were achieved to ensure excellent electrochemical performance. ${ }^{24}$ As a precursor, strong oxidizing permanganate could react with reductive carbon substrates and form manganese oxides. Owing to the existence of various $\mathrm{Mn}$ valance $\left(\mathrm{Mn}^{2+}, \mathrm{Mn}^{3+}, \mathrm{Mn}^{4+}\right)$, the composition of manganese oxides was attributed to the reaction conditions, such as the radios of permanganate/reducing agent, ${ }^{25}$ reaction temperature, ${ }^{26} \mathrm{pH}$ value of solution. ${ }^{27}$ In summary, it was found that the carbon substrates have significant effects on the structure and composition of manganese oxides/carbon composite electrodes. The previous researches 
were focused on the preparation method and carbon substrates type of manganese oxides/carbon electrodes, ${ }^{13-15,21-24}$ however the effect of carbon substrates on the composition and electrochemical performance of composite electrodes was limited.

In this study, glucose (GS) was used as raw material to prepare poly glucose (PGS) as carbon substrates by hydrothermal reaction, and composite electrode material (manganese oxide supported on PGS) was prepared by using $\mathrm{KMnO}_{4}$ as manganese source. In order to study the effect of the carbon substrate on the structure and properties of composite electrode materials, the changes of the composition of the composite electrode materials were investigated in different weight ratio of $\mathrm{KMnO}_{4} / \mathrm{PGS}$.

\section{EXPERIMENTAL}

\section{Preparation of poly glucose (PGS)}

The preparation of poly glucose (PGS) was described in other references. ${ }^{28-30}$ In this typical synthesis procedure, $3 \mathrm{~g}$ of glucose (AR grade, Sinopharm Chemical Reagent Co, Ltd) was dissolved in 30 $\mathrm{mL}$ deionized water, and then the solution was transferred into 50 $\mathrm{mL}$ stainless steel autoclave and maintained at $180{ }^{\circ} \mathrm{C}$ for $6 \mathrm{~h}$. The brown products were washed respectively by water and alcohol for five times, and then dried at $80^{\circ} \mathrm{C}$ for $5 \mathrm{~h}$.

Preparation of manganese oxide supported on PGS

The preparation of manganese oxide usually can be summarized into two methods. One preparation is the oxidation of low state of $\mathrm{Mn}$ species $\left(\mathrm{Mn}^{2+}\right)$ by oxidizing agents, such as $\mathrm{KMnO}_{4}$ and $\left(\mathrm{NH}_{4}\right)_{2} \mathrm{~S}_{2} \mathrm{O}_{8} \cdot{ }^{31,32}$ The other preparation is the reduction of $\mathrm{KMnO}_{4}$ by reducing agents, such as ethanol, ${ }^{33} \mathrm{PEG},{ }^{34}$ carbon. ${ }^{35}$ In this article, the manganese oxide/PGS composite electrodes were prepared with hydrothermal method by using $\mathrm{KMnO}_{4}$ as manganese source. PGS powder as-prepared $(10 \mathrm{mg}$ ) was dispersed in deionized water (30 $\mathrm{mL}$ ) by ultrasonic vibration for $2 \mathrm{~h}$, and then $\mathrm{KMnO}_{4}$ powder $(30$ $\mathrm{mg}$ ) was added into above suspension and stirred by magnetic bar. Subsequently, the mixture was transferred into a stainless steel with a capacity of $30 \mathrm{~mL}$ and heated at $100{ }^{\circ} \mathrm{C}$ for $12 \mathrm{~h}$. Finally, the autoclave was cooled to room temperature naturally. The resultant product was collected by centrifugation and repeatedly washed with deionized water. The final product was dried in a vacuum at $80{ }^{\circ} \mathrm{C}$ overnight and denoted as $\mathrm{KMnO}_{4} / \mathrm{PGS}$ (3:1). For comparison, manganese oxide/ PGS composite electrodes with different weight ratios of $\mathrm{KMnO}_{4} /$ PGS were similarly prepared and denoted as $\mathrm{KMnO}_{4} / \mathrm{PGS}$ (3:n, $\mathrm{n}=3$, $5,7,9)$. It should be noted that the addition of $\mathrm{KMnO}_{4}$ was keep constant weight (30 mg).

\section{Electrochemical measurements}

The electrochemical properties of the materials were investigated by the cyclic voltammetry (CV), galvanostatic charge/discharge (GCD) and repeating chronopotentiometry (RCP) on a $\mathrm{CHI} 660 \mathrm{E}$ electrochemical workstation (Shanghai CH Instrument Company, China) at room temperature. The fabrication of electrode: the asprepared manganese oxide/PGS, carbon black and polytetrafluoroethylene (PTFE) were mixed in a mass ratio of 70:20:10 and dispersed in ethanol. Then the mixture was coated onto a nickel foam substrate $(1 \mathrm{~cm} \times 1 \mathrm{~cm})$, and then dried at $80^{\circ} \mathrm{C}$ for $12 \mathrm{~h}$ in a vacuum. The loading mass of electrode was about $6 \mathrm{mg}$. Electrochemical measurements were carried out in a conventional three-electrode cell with $1 \mathrm{~mol} \mathrm{~L}^{-1} \mathrm{Na}_{2} \mathrm{SO}_{4}$ aqueous solution as the electrolyte. Platinum foil and a saturated calomel electrode (SCE) were used as the counter electrode and the reference electrode, respectively. CV tests were respectively done between 0 and 1.0 (vs. SCE) at different scan rates of 5 to $80 \mathrm{mV} \mathrm{s}^{-1}$. GCD curves were measured in the potential range of 0 to $1.0 \mathrm{eV}$ (vs. SCE) at different current densities of $0,1,2,4,6$, and $8 \mathrm{~A} \mathrm{~g}^{-1}$. According to the GCD curves, the specific capacitances of the electrodes were respectively calculated using the following equation:

$$
\mathrm{C}=(I \Delta t) /(m \Delta V)
$$

where $\mathrm{C}(\mathrm{Fg}-1)$ is the specific capacitance, $\mathrm{I}(\mathrm{mA})$ is charge discharge current, $\Delta \mathrm{t}(\mathrm{s})$ is the discharge time, $\mathrm{m}(\mathrm{mg})$ represents the loading mass of electroactive material, and $\Delta \mathrm{V}(\mathrm{V})$ is the potential drop in the galvanostatic discharge process. In order to test the long term chargedischarge cycling stability of the electrodes, RCP measurements were employed applying double current pulse $( \pm 2.0 \mathrm{~mA})$ for 3000 cycles.

\section{Sample characterization}

\section{$X R D$}

XRD patterns for the calcined samples were recorded with an advanced D8 powder diffractmeter (Bruker, Germany) with $\mathrm{Cu} \mathrm{K} \alpha$ radiation $(\lambda=0.154 \mathrm{~nm})$. The samples were scanned at small-angle from $0.5^{\circ}$ to $10^{\circ}(2 \theta)$ and at large-angle from $10^{\circ}$ to $80^{\circ}(2 \theta)$ with a step size of $0.02^{\circ}$, respectively. The crystallite phase was estimated with the data of Joint Committee on Powder Diffraction Standards (JCPDS).

\section{$X P S$}

XPS was recorded on a VG Mutilab 2000 spectrometer (Bruker, Germany) using an $\mathrm{Al} \mathrm{K} \alpha(\mathrm{hv}=1486.7 \mathrm{eV})$ as X-ray source. To remove charging shifts and deal with Fermi edge coupling problems, binding energies (BE) were scaled against the peak of the $\mathrm{C}-(\mathrm{C}, \mathrm{H})$ component coming from contamination carbon (set to $284.6 \mathrm{eV}$ ). The pressure of the sample chamber was less than $2 \times 10^{-8} \mathrm{~Pa}$.

\section{Raman spectroscopy}

Normal Raman experiments were performed in the dispersivemode using a Bruker Senterra Raman spectrometerequipped with an Olympus 100_ long working distance microscope objective and a charge-coupled device (CCD) detector. A Spectra Physics Cyan solid state laser, a Melles Griot He-Ne laser and a continuous wave (CW) diode laser, emitting at $488 \mathrm{~nm}, 633 \mathrm{~nm}$ and $785 \mathrm{~nm}$ respectively, were used as the excitation sources, and two holographic gratings (1800 and 1200 rulings per $\mathrm{mm}$ ) provided a spectral resolution of $3-5 \mathrm{~cm}^{-1}$. Raman analyses were carried out by collecting 1 scan with an integration time of $30 \mathrm{~s}$. The output laser power was 2 or $5 \mathrm{~mW}$ for $633 \mathrm{~nm}$ excitation

\section{RESULTS AND DISCUSSION}

\section{Microstructure characterization}

The XRD patterns of manganese oxide/PGS were shown in Figure 1. As shown in Figure 1, a broadening of diffraction peaks at $22^{\circ}$ was observed at PGS, indicating that the amorphous carbon in PGS. After deposited with manganese oxide, the intensity of diffraction peak at $22^{\circ}$ of PGS decreased, meanwhile other new diffraction peaks were observed with the increasing PGS content. It can be seen that the XRD diffraction peaks of MnOOH (JCPDS No. 41-1379) were observed on manganese oxide/PGS with lower content of carbon substrates $\left(\mathrm{KMnO}_{4} / \mathrm{PGS}=3: 1\right)$. When the weight ratios of $\mathrm{KMnO}_{4} / \mathrm{PGS}$ equaled to 3:3, the diffraction peaks of $\mathrm{MnOOH}$ disappeared, meanwhile the diffraction peaks of $\mathrm{Mn}_{3} \mathrm{O}_{4}$ (JCPDS No. 27-0734) was observed. With the increasing PGS content, the mixed compounds including $\mathrm{Mn}_{3} \mathrm{O}_{4}$ 
and $\mathrm{MnCO}_{3}$ (JCPDS No. 44-1472) were obtained, moreover the diffraction peaks of $\mathrm{Mn}_{3} \mathrm{O}_{4}$ were gradually weakened and completely substituted by the diffraction peaks of $\mathrm{MnCO}_{3}$ on hybrid materials with high PGS content $\left(\mathrm{KMnO}_{4} / \mathrm{PGS}=3: 9\right)$. As seen from results of $\mathrm{XRD}$, the composition of manganese oxide/PGS was depended on the content of carbon substrates (PGS). When the content of carbon substrates is lower, the major composition of manganese oxide was $\mathrm{MnOOH}$ with high valence $\mathrm{Mn}$ cation (+3), and then with increasing the content of carbon substrates, $\mathrm{MnOOH}$ was substituted by $\mathrm{Mn}_{3} \mathrm{O}_{4}$ with mixed-valence Mn cation ( +3 and +2 ), finally the conversation from $\mathrm{Mn}_{3} \mathrm{O}_{4}$ to $\mathrm{MnCO}_{3}$ was observed on manganese oxide/PGS with high carbon substrates.

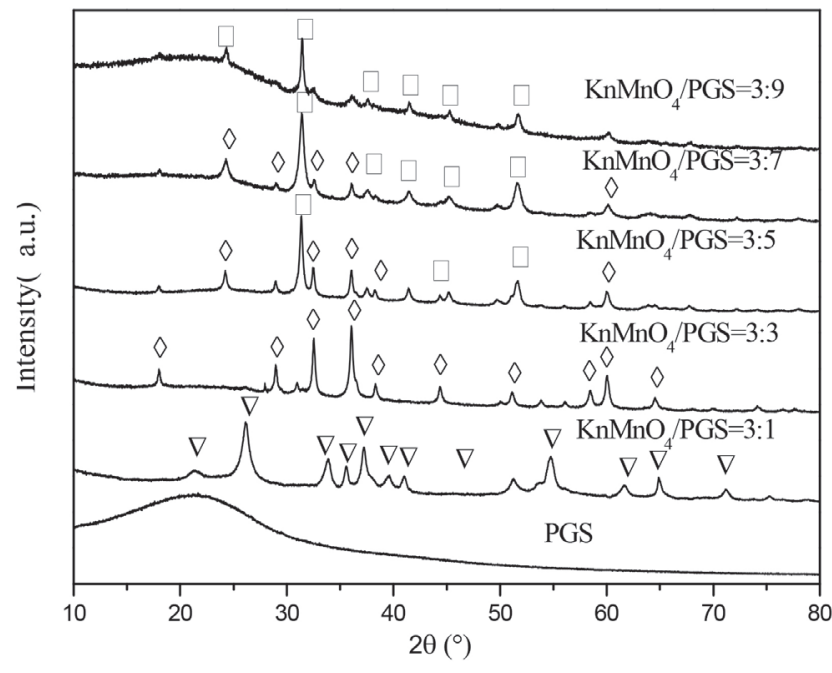

Figure 1. XRD patterns of manganese oxide/PGS with different weight ratios of $\mathrm{KMnO}_{4} / \mathrm{PGS} . \nabla: \mathrm{MnOOH}, \diamond: \mathrm{Mn}_{3} \mathrm{O}_{4}, \square: \mathrm{MnCO}_{3}$

\section{Raman spectroscopy}

To further confirm the composition of manganese oxide in the manganese oxide/PGS hybrid materials, these samples were also investigated by Raman scattering, as shown in Figure 2. For the Raman spectrum of manganese oxide/PGS $\left(\mathrm{KMnO}_{4} / \mathrm{PGS}=3: 1\right)$ with lower PGS content, two peaks at 362 and $558 \mathrm{~cm}^{-1}$ were observed and could be assigned to the presence of $\mathrm{MnOOH} .^{36}$

As for manganese oxide/PGS with $\mathrm{KMnO}_{4} / \mathrm{PGS}=3: 3$, the peaks of $\mathrm{MnOOH}$ disappeared, meanwhile new peaks centered at 366 and $651 \mathrm{~cm}^{-1}$ were observed, which can be assigned to $\mathrm{Mn}_{3} \mathrm{O}_{4} \cdot{ }^{37}$ With the increasing content of carbon substrates (PGS), the peak intensity of $\mathrm{Mn}_{3} \mathrm{O}_{4}$ was gradually weakened, furthermore a new peak centered at $730 \mathrm{~cm}^{-1}$ corresponding to $\mathrm{MnCO}_{3}$ was strengthened. And then two obvious peaks about 1080 and $730 \mathrm{~cm}^{-1}$ corresponding to $\mathrm{MnCO}_{3}$ were observed in manganese oxide/PGS with higher PGS content $\left(\mathrm{KMnO}_{4} / \mathrm{PGS}=3: 9\right) .{ }^{38}$

\section{X-ray Photoelectron spectroscopy (XPS)}

To further determine the composition of manganese oxide/PGS hybrid materials, XPS measurements were employed to analyze. The XPS spectral of Mn2p and O1s for all samples were shown in Figure $3 \mathrm{a}$ and $3 \mathrm{~b}$, respectively. As seen from Figure 3a, binding energy at $641.7 \mathrm{eV}$ and $654.6 \mathrm{eV}$ on material with $\mathrm{KMnO}_{4} / \mathrm{PGS}=3: 1$ was assigned to $\mathrm{Mn} 2 \mathrm{p}_{3 / 2}$ and $\mathrm{Mn} 2 \mathrm{p}_{1 / 2}$, which approximately equaled to the binding energy of $\mathrm{MnOOH} .{ }^{39}$ As for the material with $\mathrm{KMnO}_{4} /$ $\mathrm{PGS}=3: 3$, the binding energy at binding energy at $641.4 \mathrm{eV}$ and 654.1 $\mathrm{eV}$, and the energy separation between these peaks is $12.7 \mathrm{eV}$, which

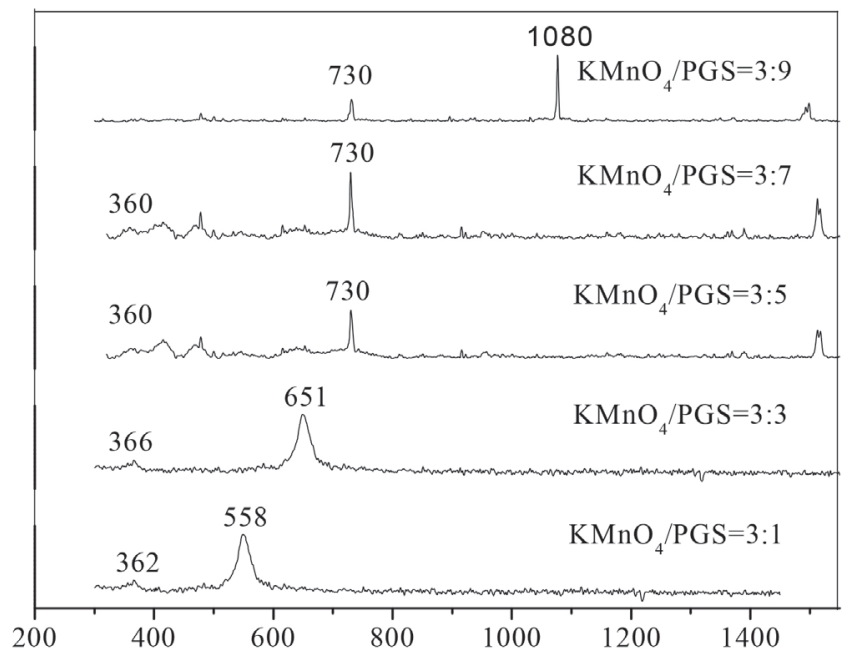

Figure 2. Raman spectrum of manganese oxide/PGS hybrid materials

is in agreement with the earlier literature on mixed valent $\mathrm{Mn}_{3} \mathrm{O}_{4} \cdot{ }^{40}$ With the increasing content of PGS, two satellite binding energy at $639.8 \mathrm{eV}$ and $652.6 \mathrm{eV}$ were observed, moreover the peak intensity increases with the increasing PGS content. According to the literature, the located binding energies around $639.8 \mathrm{eV}$ and $652.6 \mathrm{eV}$ usually are attributed to $\mathrm{Mn}^{\mathrm{II}} 2 \mathrm{p}_{3 / 2}$ and $\mathrm{Mn}^{\mathrm{II}} 2 \mathrm{p}_{1 / 2}$, respectively. ${ }^{41}$ Therefore, the proportion of $\mathrm{Mn}^{\mathrm{II}}$ in manganese oxide/carbon substrates hybrid materials increases with the increasing PGS content. When the content of PGS up to $\mathrm{KMnO}_{4} / \mathrm{PGS}=3: 9$, two binding energy located at 639.2 $\mathrm{eV}$ and $651.8 \mathrm{eV}$ can be assigned to $\mathrm{Mn}^{\mathrm{I}} 2 \mathrm{p}$. The high resolution results of $\mathrm{O} 1 \mathrm{~s}$ for all materials were shown in Figure $3 \mathrm{~b}$. As can be seen from the results, O1s binding energy of material with $\mathrm{KMnO}_{4} /$ PGS $=3: 3$ can be described as the superposition of two peaks (529.9 $\mathrm{eV}$ and $532.1 \mathrm{eV}$ ) by a Gaussian distribution, which were attributed to the $\mathrm{O}^{2-}$ and $\mathrm{OH}$ arised from $\mathrm{MnOOH}$. As for the material with $\mathrm{KMnO}_{4} / \mathrm{PGS}=3: 5$, the binding energy at $531 \mathrm{eV}$ is associated with the lattice oxygen in $\mathrm{Mn}_{3} \mathrm{O}_{4} \cdot{ }^{42}$ With the increasing content of PGS, three peaks were observed on materials, locating at $530.8 \mathrm{eV}, 531.8$ $\mathrm{eV}$ and $533.2 \mathrm{eV}$, moreover the intensity of peak at $531.8 \mathrm{eV}$ gradually increases, while the $\mathrm{O} 1 \mathrm{~s}$ peak located $530.8 \mathrm{eV}$ presented an opposite change trend. The binding energy at $530.8 \mathrm{eV}$ is associated with the lattice oxygen in $\mathrm{Mn}_{3} \mathrm{O}_{4}$, and higher binding energy at $531.8 \mathrm{eV}$ is assigned to oxygen in $\mathrm{CO}_{3}{ }^{2-} \cdot{ }^{43} \mathrm{As}$ seen from the results of $\mathrm{O} 1 \mathrm{~s}$ binding energy, when the PGS content is lower, the composition of manganese oxide in hybrid material is single-component oxide $(\mathrm{MnOOH}$ or $\mathrm{Mn}_{3} \mathrm{O}_{4}$ ). With increasing PGS content, a mixture of $\mathrm{Mn}_{3} \mathrm{O}_{4}$ and $\mathrm{MnCO}_{3}$ was observed, furthermore proportion of $\mathrm{MnCO}_{3}$ in mixture also increased, and up to higher PGS content $\left(\mathrm{KMnO}_{4} / \mathrm{PGS}=3: 9\right)$, single-component $\mathrm{MnCO}_{3}$ was founded on hybrid material. These conclusions are in agreement with the characterization results of XRD and Raman spectra.

\section{Scheme of fabrication process of manganese oxide/PGS hybrid materials}

The hybrid materials were prepared by hydrothermal as described earlier in experiment section. The redox reaction between $\mathrm{KMnO}_{4}$ and carbon substrates (PGS) at $100{ }^{\circ} \mathrm{C}$ in hydrothermal condition influenced the composition of hybrid materials. A large number of manganese oxides are available owing to the different oxidation states of manganese (II, III, and IV). For the reduction reaction of $\mathrm{KMnO}_{4}$ to manganese oxide, the composition of final products will depend on content of reducing agent. 

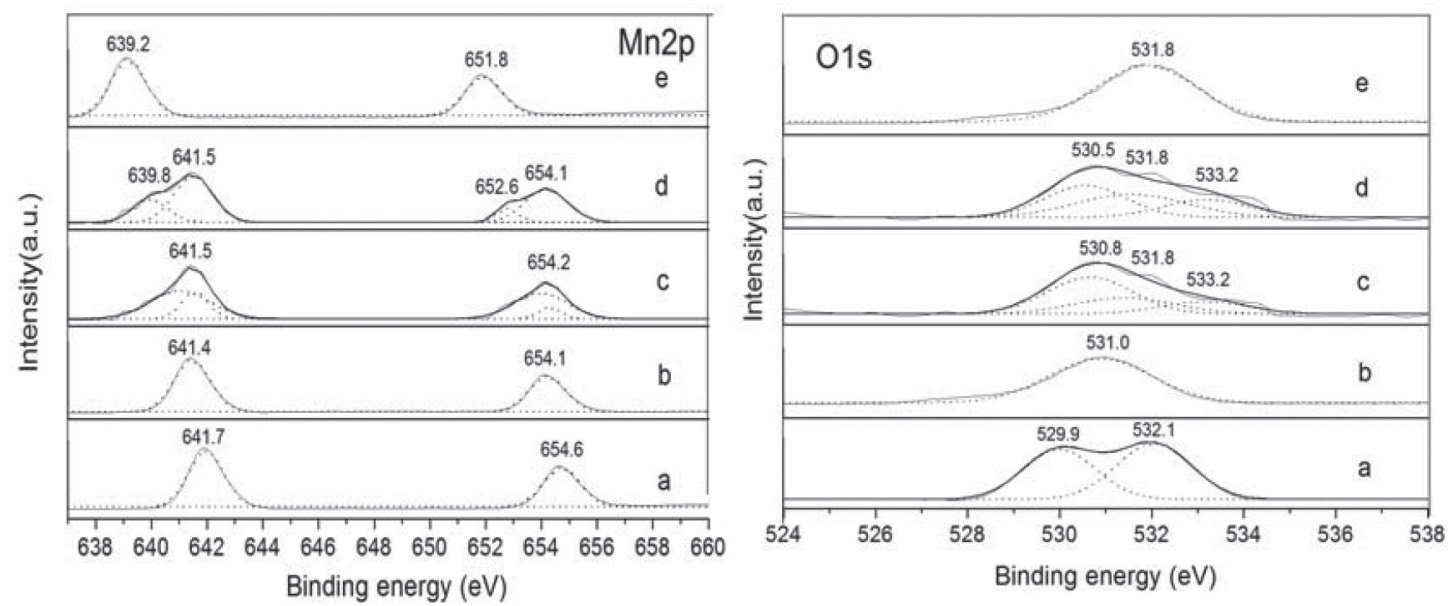

Figure 3. XPS spectra of $M n 2 p$ and $O$ 1s on the hybrid materials with different $P G S$ contents: $\left(\right.$ a) $K M n O_{4} / P G S=3: 1,(b) K M n O_{4} / P G S=3: 3,(c) K M n O_{4} / P G S=3: 5$, (d) $\mathrm{KMnO}_{4} / \mathrm{PGS}=3: 7$, (e) $\mathrm{KMnO}_{4} / \mathrm{PGS}=3: 9$

As can be seen from results of XRD, Raman spectra and XPS, the composition of hybrid materials was greatly affected by the ratios of $\mathrm{KMnO}_{4}$ and carbon substrates (PGS). In our research, the content of $\mathrm{KMnO}_{4}$ is constant, so the reaction product was greatly affected by the content of reducible agent (PGS). When the mixed $\mathrm{KMnO}_{4}$ solution with lower PGS content $\left(\mathrm{KMnO}_{4} / \mathrm{PGS}=3: 1\right)$ reacted under hydrothermal condition and formed $\mathrm{MnOOH}$. According to the literature, the formation of $\mathrm{MnOOH}$ should undergo a twostep reaction process, which is the self-hydrolysis of $\mathrm{KMnO}_{4}$ to $\mathrm{MnO}_{2}$ in solution and then further reduction of $\mathrm{MnO}_{2}$ to $\mathrm{MnOOH}$. Firstly, $\mathrm{MnO}_{4}{ }^{-}$anions in solution tend to oxidize water with the concurrent evolution of oxygen and spontaneous precipitation of $\mathrm{MnO}_{2}$, and then the formed $\mathrm{MnO}_{2}$ transformed into $\mathrm{MnOOH}$ according to Eq. (2) during the hydrothermal process due to the self generated pressure in the autoclave. ${ }^{44}$ It is very unfortunately that $\mathrm{MnO}_{2}$ was not detected in this work, however many research also confirmed that $\mathrm{MnOOH}$ is the final product, when the reducing agent was low. ${ }^{45-48}$

$$
\begin{gathered}
4 \mathrm{KMnO}_{4}+2 \mathrm{H}_{2} \mathrm{O} \rightarrow 4 \mathrm{MnO}_{2}+4 \mathrm{KOH}+3 \mathrm{O}_{2} \\
4 \mathrm{MnO}_{2}+2 \mathrm{H}_{2} \mathrm{O} \rightarrow 4 \mathrm{MnOOH}+\mathrm{O}_{2}
\end{gathered}
$$

With the increasing reducing agent (PGS) content, the reducing atmosphere is becoming stronger, $\mathrm{MnOOH}$ become unstable in the system and some of it will dehydrate to produce $\mathrm{Mn}_{3} \mathrm{O}_{4} \cdot{ }^{49}$ Therefore, single $\mathrm{Mn}_{3} \mathrm{O}_{4}$ was observed on hybrid material with $\mathrm{KMnO}_{4} / \mathrm{PGS}=3: 3$.

$$
\mathrm{MnOOH} \stackrel{\text { Reduction }}{\longrightarrow} \mathrm{Mn}_{3} \mathrm{O}_{4}
$$

When the further increasing reducing agent (PGS) content, the reducing atmosphere are power enough to reduce partial Mn species of $\mathrm{Mn}_{3} \mathrm{O}_{4}$ to $\mathrm{Mn}^{2+}$, meanwhile part of PGS will be oxidized into $\mathrm{CO}_{3}{ }^{2-}$, which leads to the formation of $\mathrm{MnCO}_{3} \cdot{ }^{50}$ When the reducing agent (PGS) content is higher, most of Mn species was reduced into $\mathrm{Mn}^{2+}$, so single phase $\mathrm{MnCO}_{3}$ was founded on hybrid material with $\mathrm{KMnO}_{4} / \mathrm{PGS}=3: 9$. The scheme of fabrication process of manganese oxide/PGS hybrid materials was shown in Figure 4.

$$
\begin{gathered}
\text { PGS } \stackrel{\text { Oxidation }}{\longrightarrow} \mathrm{CO}_{3}^{2-} \\
\mathrm{Mn}_{3} \mathrm{O}_{4} \stackrel{\text { Reduction }}{\longrightarrow} \mathrm{Mn}^{2+} \stackrel{\mathrm{CO}_{2-}^{3-}}{\longrightarrow} \mathrm{MnCO}_{3}
\end{gathered}
$$

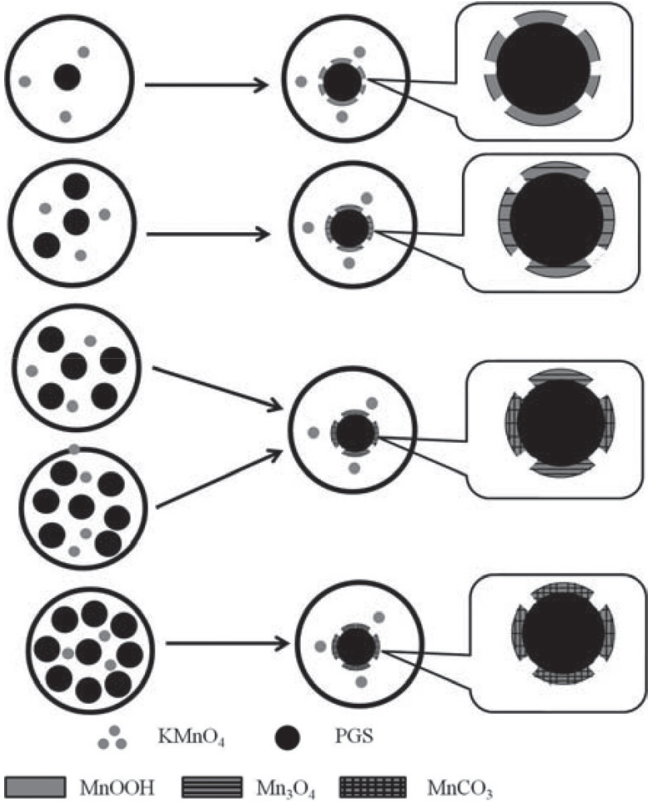

Figure 4. Scheme of fabrication process of manganese oxide/PGS hybrid materials

Electrochemical property of manganese oxide/PGS hybrid materials

Galvanostatic charge/discharge curves of the electrodes

In order to investigate the capability of the materials, Galvanostatic charge-discharge (GCD) performance measurements were carried out in $1.0 \mathrm{~mol} / \mathrm{L} \mathrm{Na}_{2} \mathrm{SO}_{4}$ at different constant current densities, as shown in Figure 5a-f. For hybrid materials with low and high $\mathrm{KMnO}_{4} / \mathrm{PGS}(3: 1$ and 3:9), rapid charge-discharge rates and a little deviation from symmetrical variations of the voltage were found (Figure 5a and 5e). However, better charge-discharge performance and linear symmetry were displayed in other hybrid materials (Figure 5b-5d). In fact, $\mathrm{MnO}_{2}$ and $\mathrm{Mn}_{3} \mathrm{O}_{4}$ usually display excellent charge-discharge performance, which could be attributed to reversible redox transitions involving the exchange of protons and/or cations with the electrolyte, as well as the transitions between $\mathrm{Mn}$ species with different valence stats $\left(\mathrm{Mn}^{2+}\right.$, $\left.\mathrm{Mn}^{3+}, \mathrm{Mn}^{4+}\right) .{ }^{51,52}$ According to the results of XRD, Raman spectroscopy and XPS, single manganese oxide $\left(\mathrm{MnOOH}\right.$ and $\mathrm{MnCO}_{3}$ ) was formed on hybrid materials with low and high $\mathrm{KMnO}_{4} / \mathrm{PGS}$ (3:1 and 3:9), 
however manganese oxides with mixed $\mathrm{Mn}$ valence states $\left(\mathrm{Mn}^{2+}, \mathrm{Mn}^{3+}\right)$ were found on other materials, such as $\mathrm{Mn}_{3} \mathrm{O}_{4}$ or mixture of $\mathrm{Mn}_{3} \mathrm{O}_{4}$ and $\mathrm{MnCO}_{3}$. Therefore, higher charge-discharge performance and linear symmetry were displayed on materials with mixed Mn valence states, such as $\mathrm{Mn}_{3} \mathrm{O}_{4}$ or mixture of $\mathrm{Mn}_{3} \mathrm{O}_{4}$ and $\mathrm{MnCO}_{3}$, especially for material with $\mathrm{KMnO}_{4} / \mathrm{PGS}=3: 3$ and 3:5 (5b and 5c). Figure 5f shows the charge-discharge curve of all hybrid materials at the same current density of $2 \mathrm{~A} \mathrm{~g} \mathrm{~g}^{-1}$. The specific capacitance of the electrode can be calculated according to $\mathrm{C}=(\mathrm{I} \cdot \Delta \mathrm{t}) /(\mathrm{m} \cdot \Delta \mathrm{V})$ from the discharge curves. The specific capacitance of hybrid materials with different $\mathrm{KMnO}_{4} /$ PGS is $31.85,74.21,54.46,44.74$ and $32.60 \mathrm{~F} \mathrm{~g}^{-1}$, and higher specific capacitance of hybrid materials with $\mathrm{KMnO}_{4} / \mathrm{PGS}=3: 3\left(75.21 \mathrm{~F} \mathrm{~g}^{-1}\right)$ than that of other materials. On the other hand, the specific capacitance decreases obviously when $\mathrm{Mn}_{3} \mathrm{O}_{4}$ is transformed to $\mathrm{MnCO}_{3}$, this is contributed to the poor pseudocapacitive performance of $\mathrm{MnOOH}$ and $\mathrm{MnCO}_{3}$ compared to $\mathrm{Mn}_{3} \mathrm{O}_{4}$.

Recently, Zhang et al. synthesized MnOOH-graphene nanocomposite by facile way and obtained maximum supercapacitance
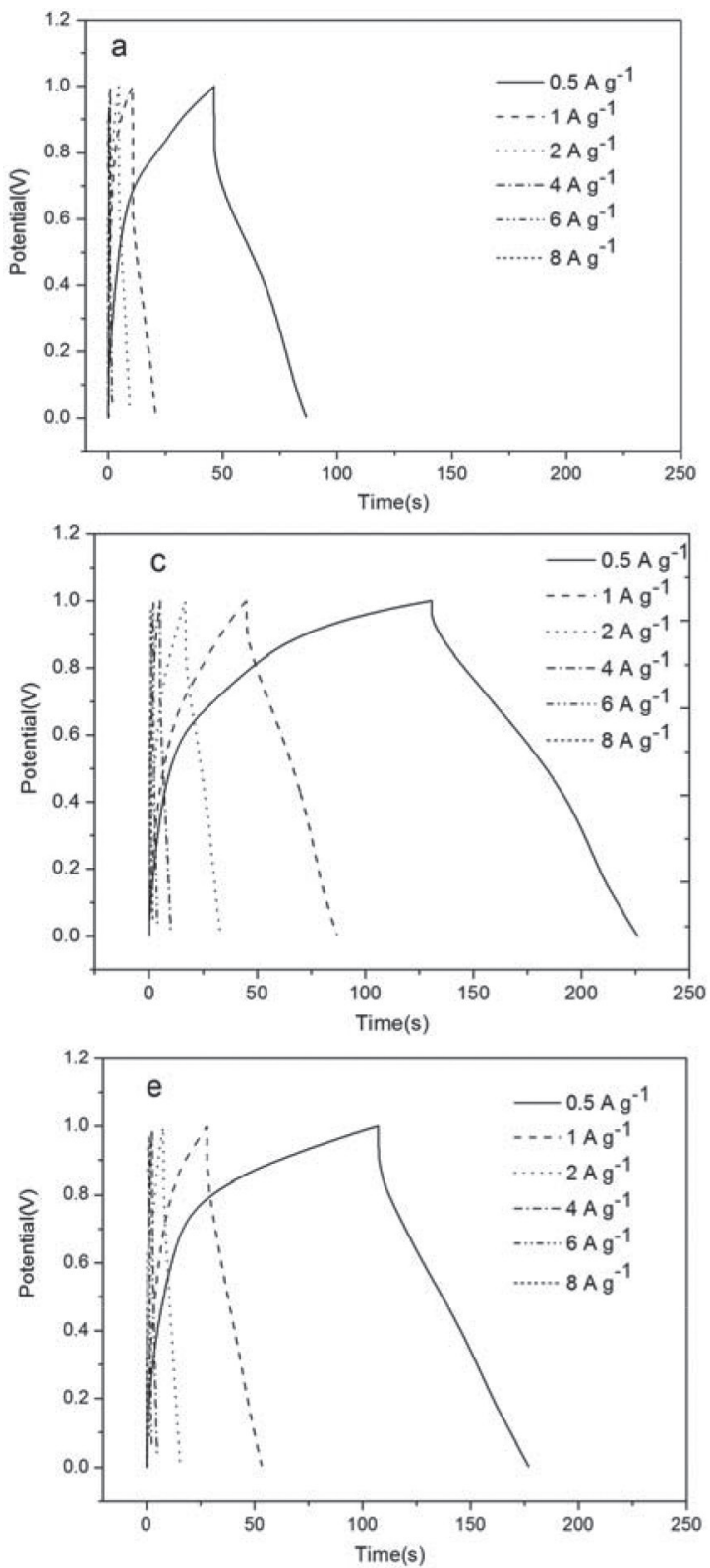

of $127 \mathrm{~F} \mathrm{~g}^{-1}$ at a current density at the current density of $4 \mathrm{~A} \mathrm{~g}^{-1} \cdot{ }^{53} \mathrm{C}$. D. Lokhande et al. reported specific capacitances of $344 \mathrm{~F} \mathrm{~g}^{-1}$ at a scan rate of $5 \mathrm{mV} \mathrm{s}^{-1}$ for $\mathrm{Mn}_{3} \mathrm{O}_{4}$ /graphene composite prepared. ${ }^{54} \mathrm{P}$. Balaya et al. reported a specific capacitance of $216 \mathrm{~F} \mathrm{~g} \mathrm{~g}^{-1}$ for $\mathrm{MnCO}_{3}{ }^{55}$ The specific capacitance of hybrid materials with different KMnO4/PGS is $31.85,74.21,54.46,44.74$ and $32.60 \mathrm{~F} \mathrm{~g}-1$, and higher specific capacitance of hybrid materials with $\mathrm{KMnO} 4 / \mathrm{PGS}=3: 3\left(75.21 \mathrm{~F} \mathrm{~g}^{-1}\right)$ than that of other materials. The value obtained in the present study is comparatively lower than previously reported values.

The improvements in energy density $(E)$ can be achieved by maximizing the specific capacitance $(C)$ and/or the cell voltage $(V)$.

$$
E=\frac{C V^{2}}{2}
$$

According to the equation (6), the energy density $(E)$ of all composite hybrid material is $11.32,22.39,19.36,15.91$ and $11.59 \mathrm{Wh} /$ $\mathrm{kg}$, and results indicate that the energy density increases firstly, and reaches a maximum value $(22.39 \mathrm{Wh} / \mathrm{kg})$ on material with $\mathrm{KMnO}_{4} /$
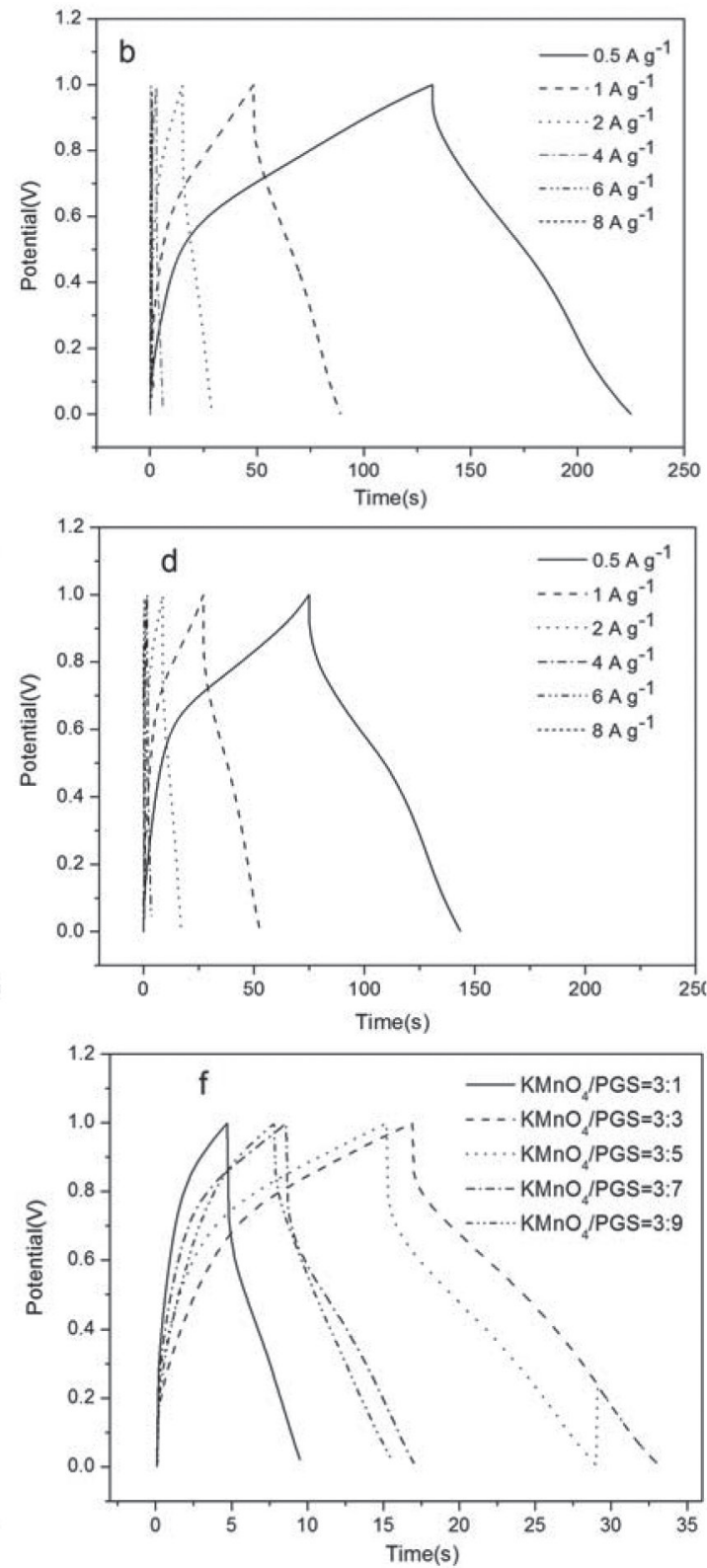

Figure 5. (a)-(e): Galvanostatic charge-discharge curves of the products as prepared in 1mol/L $\mathrm{Na}_{2} \mathrm{SO}_{4}$ aqueous electrolyte, (f) Galvanostatic charge-discharge curves of hybrid materials at $2 \mathrm{~A}^{-1}$ 
$\mathrm{PGS}=3: 3$, and then gradually decreases to lower value $(22.39 \mathrm{Wh} / \mathrm{kg})$, when the PGS content up to highest value $\left(\mathrm{KMnO}_{4} / \mathrm{PGS}=3: 9\right)$. These effects are in agreement with trend change of specific capacitance.

The specific capacitance of hybrid materials in this article with similar manganese oxide electrode materials. Much lower specific capacitance $\left(75.21 \mathrm{~F} \mathrm{~g}^{-1}\right)$ was found in this article than that of similar research, which was probably attributed to the property of support (PGS). According to the preparation method of PGS, glucose was used as raw material to prepare PGS in hydrothermal condition, and there may be many oxygen-containing function groups on the PGS support surface. These oxygen-containing functional groups could trigger the quick Faradaic reactions in electrochemistry process, which lead to rapid charge-discharge rates and a little deviation from symmetrical variations of the voltage during the charging-discharging process. ${ }^{56}$ Therefore, much lower specific capacitance was found in this article than that of similar research. It should be noted that this explanation maybe not rigorous, which should be further confirmed.
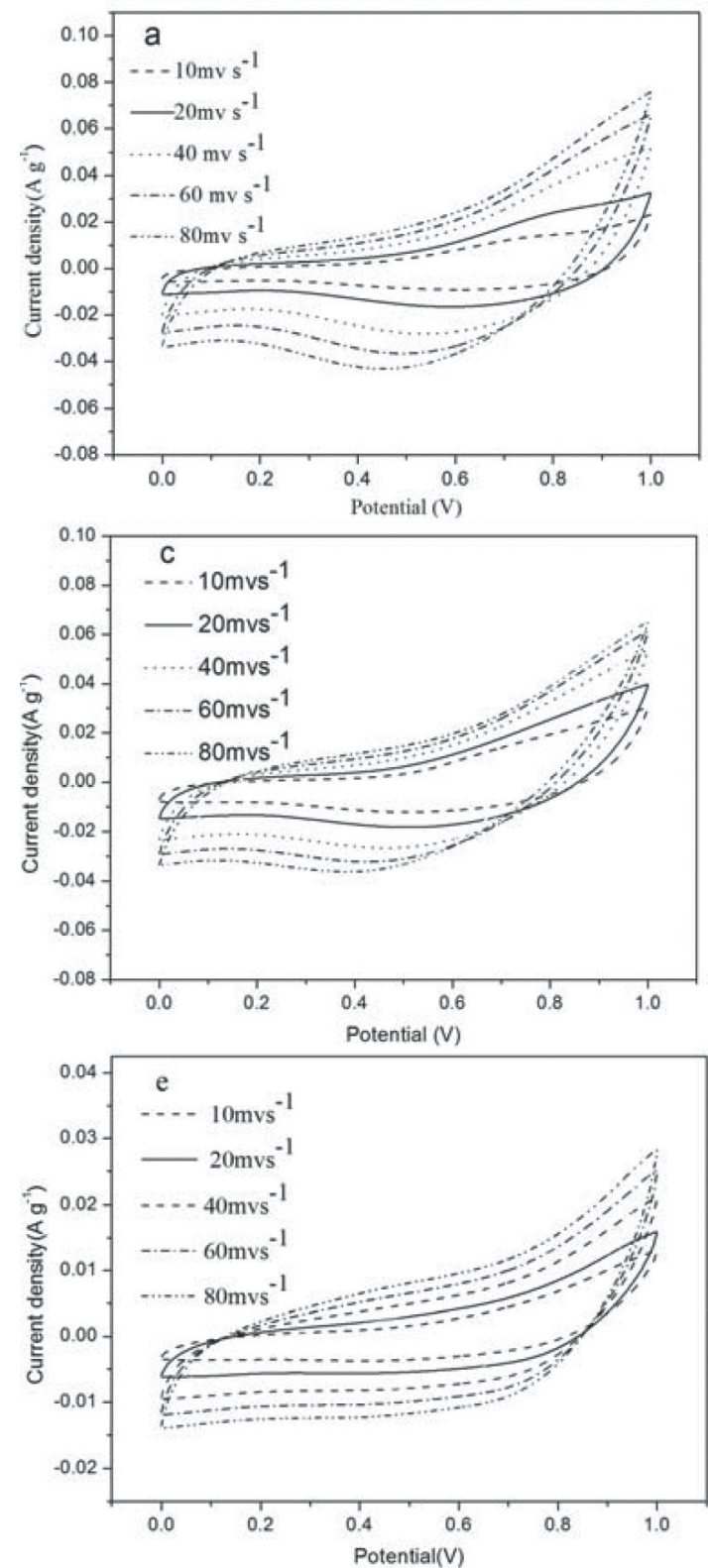

\section{Cyclic voltammogram (CV) curves of the electrodes}

Figure 6(a)-(e) shows cyclic voltammetry curves of the products as prepared in $1 \mathrm{~mol} / \mathrm{L} \mathrm{Na}_{2} \mathrm{SO}_{4}$ aqueous electrolyte at scan rates of $10,20,40,60$ and $80 \mathrm{mV} / \mathrm{s}$. For all the samples, the CV curves exhibit a little deviation from rectangular shape, and these effects are more obvious at high scan rates, indicating the presence of pseudocapacitance. Moreover, in comparison with hybrid material with $\mathrm{KMnO}_{4} / \mathrm{PGS}=3: 3$, the deviation from rectangularity of the $\mathrm{CV}$ curve for other samples become obvious as the scan rate increases, especially for $\mathrm{KMnO}_{4} / \mathrm{PGS}=3: 9$. The distorted rectangularity of the $\mathrm{CV}$ curve was probably ascribed to the charge of ion transplant surrounding, for which the ions can only reach the outer of the electrode and not enter into the interior pore at high scan rate. ${ }^{57,58} \mathrm{In}$ addition, hybrid material with $\mathrm{KMnO}_{4} / \mathrm{PGS}=3: 3$ shows two redox reaction peaks, while these peaks are not obvious for other samples, especially for $\mathrm{KMnO}_{4} / \mathrm{PGS}=3: 9$, in which the redox reaction peaks
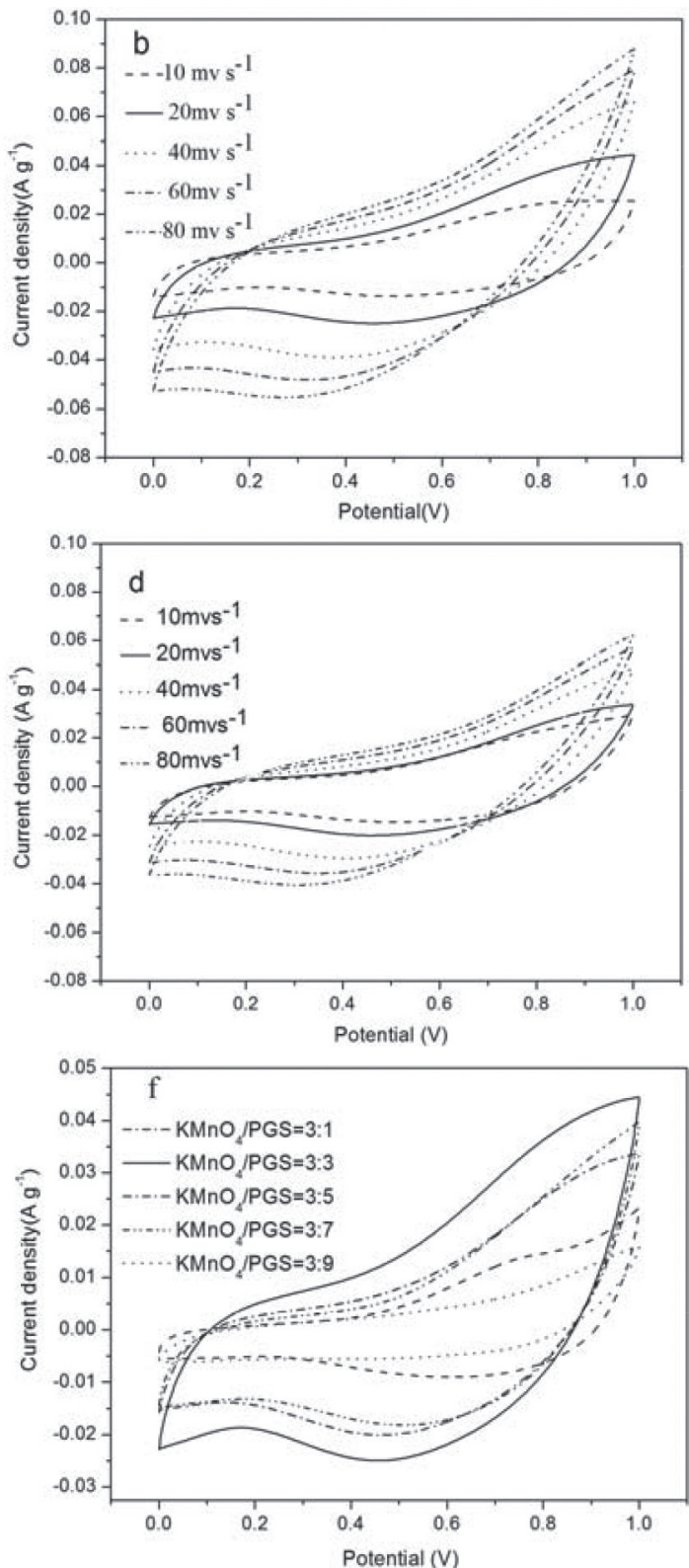

Figure 6. Cyclic voltammetry curves of the products as prepared in 1mol/L $\mathrm{Na}_{2} \mathrm{SO}_{4}$ aqueous electrolyte: (a)-(e) specific capacitances of hybrid materials at

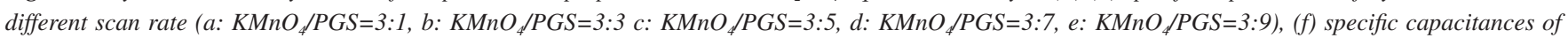
hybrid materials at different scan rate of $20 \mathrm{mV} \mathrm{s}^{-1}$ 
can almost not be observed. As for hybrid material with $\mathrm{KMnO}_{4} /$ PGS $=3: 3$, the anodic peaks is due to the oxidation of $\mathrm{Mn}_{3} \mathrm{O}_{4}$ and the cathodic peak is for the reverse process.

The CV curves of hybrid materials at low scan rate $\left(20 \mathrm{mV} \mathrm{s}^{-1}\right)$ were shown in Figure 6(e). In comparison with other samples, the $\mathrm{CV}$ curve for hybrid material with $\mathrm{KMnO}_{4} / \mathrm{PGS}=3: 3$ still retain better rectangular shape, moreover, the current density of the $\mathrm{CV}$ curve for hybrid material with $\mathrm{KMnO}_{4} / \mathrm{PGS}=3: 3$ increase significantly compared to those for other samples, which indicates that the hybrid material with $\mathrm{KMnO}_{4} / \mathrm{PGS}=3: 3$ can deliver much higher capacitance. However, poor current density and rectangularity for materials with $\mathrm{KMnO}_{4} / \mathrm{PGS}=3: 1$ and $\mathrm{KMnO}_{4} / \mathrm{PGS}=3: 9$ show lower capacitance. According to the results of GCD, lower specific capacitance $(31.85$ F. $\mathrm{g}^{-1}$ ) was calculated on hybrid material with $\mathrm{KMnO}_{4} / \mathrm{PGS}=3: 1$, and specific capacitance was improved and achieved a maximum (74.21 $\mathrm{F} \mathrm{g}^{-1}$ ) for hybrid material with $\mathrm{KMnO}_{4} / \mathrm{PGS}=3: 3$, and then reduced to $32.60 \mathrm{~F} \mathrm{~g}^{-1}$ with the further increasing carbon substrates. Compared to $\mathrm{KMnO}_{4} / \mathrm{PGS}=3: 1$ (31.85 $\left.\mathrm{F} \mathrm{g}^{-1}\right)$, higher carbon substrates (PGS) on $\mathrm{KMnO}_{4} / \mathrm{PGS}=3: 3$ will promote the electronic conductivity of electrodes, meanwhile higher pseudocapacitive performance of $\mathrm{MnOOH}$ than that of $\mathrm{MnCO}_{3}$, resulting in higher specific capacitance of $\mathrm{KMnO}_{4} / \mathrm{PGS}=3: 3\left(74.21 \mathrm{~F} \mathrm{~g}^{-1}\right)$. It should be noted that lower electrochemical properties was found on $\mathrm{MnCO}_{3}$ in comparison with $\mathrm{Mn}_{3} \mathrm{O}_{4}$. Aijun et. al. also discovered that the reducing specific capacitance was found on $\mathrm{MnCO}_{3} / \mathrm{Mn}_{3} \mathrm{O}_{4}$ hybrid materials with the increasing molar ratios of $\mathrm{MnCO}_{3}$ to $\mathrm{Mn}_{3} \mathrm{O}_{4}{ }^{59}$ In this paper, the characterization results of XRD and Raman indicated that proportion of $\mathrm{MnCO}_{3}$ on hybrid materials increased with the increasing content of carbon substrates (PGS). Therefore, lower specific capacitance was found on hybrid material with $\mathrm{KMnO}_{4} / \mathrm{PGS}=3$ :9. In summary, the specific capacitance decreases obviously when $\mathrm{Mn}_{3} \mathrm{O}_{4}$ is transformed to $\mathrm{MnCO}_{3}$. This was attributed to the poor pseudocapacitive performance of $\mathrm{MnOOH}$ and $\mathrm{MnCO}_{3}$ compared to $\mathrm{Mn}_{3} \mathrm{O}_{4}$.

\section{Charge-discharge cycling test of the electrodes}

The stability of capacitance was investigated by galvanostatic charge-discharge cycling in $1 \mathrm{~mol} \mathrm{~L}^{-1} \mathrm{Na}_{2} \mathrm{SO}_{4}$ solution and shown in Figure 7. All hybrid material indicate good charge-discharge cycling stability except for material with $\mathrm{KMnO}_{4} / \mathrm{PGS}=3: 1$. As for the material with $\mathrm{KMnO}_{4} / \mathrm{PGS}=3: 3$, the specific capacitance

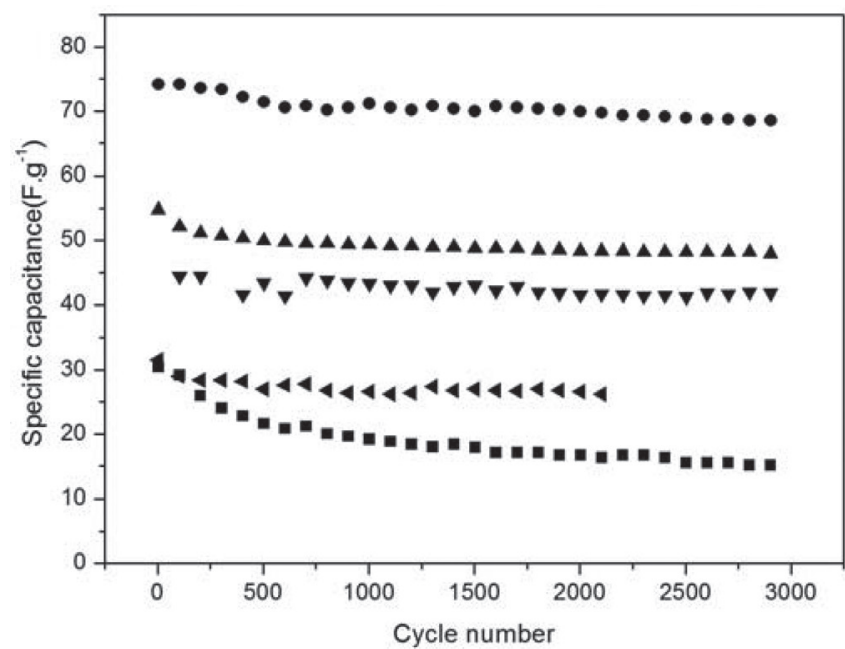

Figure 7. Charge-discharge cycling test in $1 \mathrm{M} \mathrm{Na}_{2} \mathrm{SO}_{4}$ electrolyte at the

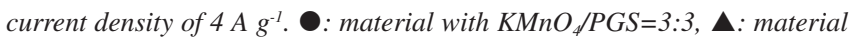
with $K_{M n O} / P G S=3: 5, \boldsymbol{\nabla}$ : material with $K M n O_{4} / P G S=3: 7, \quad$ : material with $\mathrm{KMnO}_{4} / P G S=3: 9$, $\mathbf{\square}$ : material with $\mathrm{KMnO}_{4} / P G S=3: 1$ exhibit excellent stability and retain $91.86 \%$ of its initial specific capacitance after 3000 cycles. However, an obvious decrease $(52.65 \%)$ in specific capacitance was observed on material with $\mathrm{KMnO}_{4} / \mathrm{PGS}=3: 1$. This demonstrates that material with $\mathrm{KMnO}_{4} /$ $\mathrm{PGS}=3: 3$ should be a good candidate as a material for supercapacitor electrodes.

\section{CONCLUSION}

In summary, composite electrode material of manganese oxide supported on PGS was prepared via hydrothermal reaction of $\mathrm{KMnO}_{4}$ and PGS. The results of XRD, Raman spectroscopy and XPS characterization indicate that the composition of the composite electrode materials was investigated in different weight ratio of $\mathrm{KMnO}_{4} / \mathrm{PGS}$. When the PGS content is lower, the composition of manganese oxide in hybrid material is single-component oxide $\left(\mathrm{MnOOH}\right.$ or $\left.\mathrm{Mn}_{3} \mathrm{O}_{4}\right)$. With the increasing PGS content, a mixture of $\mathrm{Mn}_{3} \mathrm{O}_{4}$ and $\mathrm{MnCO}_{3}$ was observed, furthermore proportion of $\mathrm{MnCO}_{3}$ in mixture also increased, and up to higher PGS content $\left(\mathrm{KMnO}_{4} /\right.$ $\mathrm{PGS}=3: 9$ ), single-component $\mathrm{MnCO}_{3}$ was founded on hybrid material. In addition, the change of composition of hybrid materials also led to an obvious difference in electrochemical performance. With the increase of the PGS content, the specific capacitance of hybrid materials increases firstly, and reaches the maximum with the weight ratio of $\mathrm{KMnO}_{4} / \mathrm{PGS}$ equal to 3:3, and then gradually decreases. This was attributed to the higher electrochemical performance of $\mathrm{Mn}_{3} \mathrm{O}_{4}$ than that of $\mathrm{MnOOH}$ and $\mathrm{MnCO}_{3}$.

In addition, the amount of support also has great influence on the electrochemical properties of composite materials. Compared to material with low carbon substrates $\left(\mathrm{KMnO}_{4} / \mathrm{PGS}=3: 1\right)$, higher specific capacitance and electrochemical performance was found on hybrid material with $\mathrm{KMnO}_{4} / \mathrm{PGS}=3: 3$, meanwhile, specific capacitance decreases obviously when $\mathrm{Mn}_{3} \mathrm{O}_{4}$ is transformed to $\mathrm{MnCO}_{3}$. This was attributed to the poor pseudocapacitive performance of $\mathrm{MnOOH}$ and $\mathrm{MnCO}_{3}$ compared to $\mathrm{Mn}_{3} \mathrm{O}_{4}$.

\section{ACKNOWLEDGEMENTS}

This work is supported by Henan province university key scientific research project (16B150013), the high-level talent scientific research foundation project of Pingdingshan university.

\section{REFERENCES}

1. Wei, W. F.; Cui, X. W.; Chena, W. X.; Ivey, D. G.; Chem. Soc. Rev. 2011, 40, 1697.

2. Simon, P.; Gogotsi, Y.; Nat. Mater. 2008, 7, 845.

3. Gu, H.; Wei, H.; Guo, J.; Haldolaarachige, N.; Young, D. P.; Wei, S.; Guo, Z.; Polymer 2013, 54, 5974.

4. Wei, H.; Gu, H.; Guo, J.; Wei, S.; Liu, J.; Guo, Z.; J. Phys. Chem. C 2013, 117, 13000.

5. Wang, G. P.; Zhang, L.; Zhang, J. J.; Chem. Soc. Rev. 2012, 41, 797.

6. Wang, L.; Wang, D. L.; Electrochim. Acta 2011, 56, 5010.

7. Gund, G. S; Dubal, D. P.; Patil, B. H.; Electrochim. Acta 2013, 92, 205.

8. Xu, C. J.; Kang, F. Y.; Li, B. H.; Du, H. D.; J. Mater. Res. 2010, 25, 1421.

9. Jun, M.; Zhang, L.; J. Solid State Chem. 2015, 221, 178.

10. Gund, G. S.; Dubal, D. P.; Patil, B. H.; Electrochim. Acta 2013, 92, 205.

11. Zhang, L. L.; Zhao, X.; Chem. Soc. Rev. 2009, 38, 2520.

12. Zhai, Y.; Dou, Y.; Zhao, D.; Fulvio, P. F.; Mayes, R. T.; Dai, S.; Adv. Mater. 2011, 23, 4828.

13. Yoon, Y.; Cho, W.; Lim, J.; Choi, D.; J. Power Sources 2001, 101, 126. 
14. Nardecchia, S.; Carriazo, D.; Ferrer, M. L.; Gutiérrez, M. C.; Monte, F. D.; Chem. Soc. Rev. 2013, 42, 794.

15. Hu, S.; Zhang, S.; Pan, N.; Hsieh, Y. L.; J. Power Sources 2014, 270 , 106.

16. Wang, Q.; Li, H.; Chen, L.; Huang, X. J.; Carbon 2001, 39, 2211.

17. Zheng, M. B.; Cao, J. M.; Jun, X. C.; Liu, J. S.; Ma, X.; J. Mater. Lett. 2006, 60, 2991.

18. Zhuang, Z. H.; Yang, Z. G.; J. Appl. Polym. Sci. 2009, 114, 3863.

19. Zheng, M. B.; Cao, J. M.; Jun, X. C.; Liu, J. S.; Ma, X.; J. Mater. Lett. 2006, 60, 2991.

20. Zhuang, Z. H.; Yang, Z. G.; J. Appl. Polym. Sci. 2009, 114, 3863.

21. Wang, G. X.; Zhang, B. L.; Yu, Z. L.; Qu, M. Z.; Solid State Ionics 2005, $176,1169$.

22. Fan, Z.; Chen, J.; Wang, M.; Cui, K.; Zhou, H.; Kuang, Y. F.; Diamond Relat. Mater. 2006, 15, 1478.

23. Subramanian, V.; Zhu, H.; Wei, B.; Electrochem. Commun. 2006, 8, 827.

24. Lee, C. Y.; Tsai, H. M.; Chuang, H. J.; Li, S. Y.; Lin, P.; Tseng, T. Y.; J. Electrochem. Soc. 2005, 152, 716.

25. Yang, Y. J.; Huang, C. D.; J Solid State Electrochem. 2010, 14, 1293.

26. Shi, X. L.; Cao, M. S.; Fang, X. Y.; Yuan, J.; Appl. Phys. Lett. 2008, 93, 183118.

27. Wen, L. Q.; Wang, Y. M.; Luo, G. A.; Sens. Actuators, B 1999, 59, 42.

28. Mi, Y. Z.; Hu, W. B.; Dan, Y. M.; Liu, Y. L.; Material Lett. 2008, 62, 1194.

29. Zhang, C. Y.; Lin, S.; Peng, J. J.; Hong, Y. Z.; Wang, Z. Y.; Jin, X. B.; Rsc Adv. 2017, 7, 6486.

30. Roberts A. D.; Xu, L.; Zhang H. F.; Chem. Soc. Rev. 2014, 43, 4341.

31. Choi, Hyun-A; Jang, H.; Hwang, H.; Choi, M.; Lim, D.; Shim, S. E.; Baeck, S. H.; Electron. Mater. Lett. 2014, 10, 957.

32. Wang, G. X.; Xu, H. F.; Lu, L; Zhao, H.; J. Mater. Chem. A 2015, 3, 1127.

33. Zhou, Y. R.; Tong, C.; Zhang. J. X.; Liu, Y.; Ren, P.; Chin. J. Chem. 2017, 38, 1294.

34. Lan, L. L.; Li, Q. J.; Gu, G. R.; Zhang, H. F.; Liu, B. B.; J. Alloy Compd. 2015, 644, 430.

35. Wu, Y. Z.; Liu, S. Q.; Zhao, K. M.; He, Z.; Yuan, H.; Lv, K.; Jia, G.; Ionics 2016, 22, 1185.

36. Folch, B.; Larionova, J.; Guari, Y.; Guérin, C.; Reibel, C.; J Solid State Chem. 2005, 178, 2368.
37. Gao, F.; Qu, J. Y.; Zhao, Z. B.; Zhou, Q.; Li, B. B.; Qiu, J. S.; Carbon 2014, 80, 640.

38. Sukhorukov, G. B.; Shchukin, D. G.; Dong, W. F.; Vinogradova, O. I.; Macromol. Chem. Phys. 2004, 205, 530.

39. Ramstedt, M.; Shchukarev, A. V.; Sjöberg, S.; Surf. Interface Anal. 2002, 34, 632 .

40. Sourav, B.; Kanak, R.; Chinnakonda, S.; Appl. Mater. Inter. 2014, 6, 2692.

41. Tang, C. L.; Huang, Y. H.; Zeng, H.; Zhang, Z. Q.; Chem. Eng. J. 2014, $244,97$.

42. Huang, H. W.; Yu, Q.; Peng, X. S.; Ye, Z. Z.; Chem. Commun. 2011, 47, 12831.

43. Wang, G; Huang, B. B.; Lou, Z. Z.; Wang, Z. Y.; Dai, Y.; Appl. Catal., B 2016, 180, 6 .

44. Yu, C.; Joong, J. T.; Hua, C. Z.; Langmuir 2005, 21, 1074.

45. Sun, W.; Hsu, A.; Chen, R. R.; J. Power Sources 2013, 242, 78.

46. Mei, J.; Zhang, L.; J. Solid State Chem. 2015, 221, 178.

47. Cao, Y. B.; Xiao, Y. H.; Gong, Y. Y.; Wang, C. F.; Li, F.; Electrochim. Acta 2014, 127, 200.

48. Wang, L.; Wang, D. L.; Electrochim. Acta 2011, 56, 5010.

49. Xia, H.; Wang, Y.; Lin, J. Y.; Lu, L.; Nanoscale Res. Lett. 2012, 7, 33.

50. Wang, X.; Li, Y. D.; Mater. Chem. Phys. 2003, 82, 419.

51. Miller, J. R.; Simon, P.; Science 2008, 321, 651.

52. Wang, G. P.; Zhang, L.; Zhang, J. J.; Chem. Soc. Rev. 2011, 41, 797.

53. Mei, J.; Zhang, L.; J Solid. State. Chem. 2015, 221, 178.

54. Gund, G. S.; Dubal, D. P.; Patil, B. H.; Shinde, S. S.; Lokhande, C. D.; Electrochim. Acta 2013, 92, 205.

55. Devaraj, S.; Vardhan, P. V.; Liu, H. Y.; Balaya, P.; J. Solid State Electrochem. 2016, 20, 1877.

56. Xu, B.; Yue, S. F.; Sui, Z. Y.; Zhang, X. T.; Hou, S. S.; Cao, G. P.; Yang, Y. S.; Energy Environ. Sci. 2011. 4, 2826.

57. Pech, D.; Brunet, M.; Durou, H.; Huang, P. H.; Mochalin, V.; Gogotsi, Y.; Taberna, P. L.; Simon, P.; Nat. Nanotechnol. 2010, 5, 651.

58. Lang, X. Y.; Hirata, A.; Fujita, T.; Cheng, M.W.; Nat. Nanotechnol. 2011, 6, 232.

59. Aijun, G. U.; Li, Z. C.; Qian, H.; Mater. Rev. 2013, 105, 107. 